\title{
COMPORTAMENTO DOS SÓLIDOS TOTAIS NO PROCESSO DE DIGESTÃO ANAERÓBIA DE RESÍDUOS SÓLIDOS URBANOS E INDUSTRIAIS
}

\author{
Valderi Duarte Leite $^{1} \&$ Jurandyr Povinelli ${ }^{2}$
}

\begin{abstract}
RESUMO
O processo de digestão anaeróbia pode ser aplicado para bioestabilizar uma grande variedade de substratos. Neste trabalho, empregou-se o processo de digestão anaeróbia à fração orgânica putrescível dos resíduos sólidos urbanos, tomando-se como parâmetros avaliativos os sólidos totais e os sólidos totais voláteis. O trabalho foi realizado em quatro reatores anaeróbios de batelada, com capacidade unitária de $50 \mathrm{~L}$ e a análise dos seus dados mostra que é possível se empregar o processo de digestão anaeróbia a esse tipo de substrato que, além de bioestabilizar a matéria orgânica putrescível, produz gás metano, que pode ser utilizado como fonte alternativa de energia para fins domésticos e industriais.
\end{abstract}

Palavras-chave: sólidos totais, anaeróbio, resíduos sólidos urbanos

\section{BEHAVIOR OF TOTAL SOLIDS IN THE PROCESS OF ANAEROBIC DIGESTION OF URBAN AND INDUSTRIAL SOLID RESIDUES}

\begin{abstract}
The process of anaerobic digestion can be applied for the bioestabilization a great variety of substrata. In this work, the process of anaerobic digestion was used to the putrescible fraction organic matter of the urban solid residues, taken total solids and the volatile total solids as evaluation parameters. The work was carried out in four $50 \mathrm{~L}$ anaerobic batch reactors and the data analysis showed tha applicability of this anaerobic process to this substratum type. The bioestabilization of the organic matter organic also produces methane gas that can be used as alternative source of energy for domestic and industrial purposes.
\end{abstract}

Key words: total solid, anaerobic, urban solid waste

\section{INTRODUÇÃO}

Segundo a ABNT(1987) os resíduos sólidos compreendem lixo urbano, lixo hospitalar, lixo agrícola ou rural, lodo de estações de tratamento de esgotos sanitários ou industriais, resíduos gerados por equipamentos e instalações de controle de poluição e determinados líquidos, cujas características tornem inviável seu lançamento em redes públicas ou corpos receptores de água.
Os indicadores qualitativos que caracterizam o perfil brasileiro em relação aos resíduos sólidos não são nada animadores. Para se vislumbrar o que ocorre com os resíduos sólidos urbanos coletados no Brasil, constata-se que apenas $0,01 \%$ é incinerado, $1,0 \%$ tratado em usinas de compostagem, $9,0 \%$ são destinados a aterros sanitários, $12 \%$ são dispostos em aterros controlados e 78,0\% são lançados em lixões (Pereira Neto, 1993).

\footnotetext{
${ }^{1}$ Doutor em Hidráulica e Saneamento pela EESC/USP. Professor da Universidade Estadual da Paraíba, Rua Vigário Calixto 1475, Catolé. CEP 58104 - 4485, Campina Grande, PB. Fone: (083) 337 2793. E-mail: valderi@ paqtc.rpp.br

${ }^{2}$ Doutor em Hidráulica e Saneamento pela EESC/USP. Professor Titular do Departamento de Hidráulica e Saneamento da Escola de Engenharia de São Carlos/USP. Av. Carlos Botelho 1465. CEP 13560 - 970, São Carlos, SP. Fone: (016) 2749264
} 
O tratamento ou industrialização dos resíduos sólidos, é o conjunto de atividades e processos que objetiva promover a reciclagem de alguns de seus componentes, como plástico, papelão, metal e vidro, e a transformação da matéria orgânica putrescível, que é o seu maior constituinte em compostos orgânicos com características de agente condicionador de solo e fonte alternativa de energia.

No Brasil, os resíduos sólidos urbanos são constituídos, basicamente, por umidade, matéria orgânica putrescível, plástico, papel e papelão. O percentual de umidade gira em torno de $50 \%$ (em peso), dependendo da época do ano e dos hábitos e costumes da população, enquanto os $50 \%$ restantes que correspondem à fração sólida, estão presentes nos demais constituintes físico-químicos.

A concentração de sólidos refere-se ao resíduo total presente no substrato, quer seja de origem orgânica ou inorgânica, e é um indicador da massa total a ser tratada. Como no processo anaeróbio a bioconversão só irá acontecer na fração teoricamente orgânica do substrato, quanto maior a concentração de sólidos totais voláteis maior, também, deverá ser a taxa de bioconversão do resíduo.

Atualmente, a concentração de sólidos define duas alternativas de tratamento:

1. tratamento anaeróbio com baixa concentração de sólidos; em que massa orgânica putrescível é fermentada com concentração de sólidos totais variando de 4 a $8 \%$ e esta alternativa se destina à geração de gás metano, a partir de excretas humanas, resíduos animais e agrícolas. As maiores dificuldades operacionais desse processo estão relacionadas à adição de água para diluição do substrato e à conseqüente dificuldade de reutilização do material bioestabilizado;

2. tratamento anaeróbio, com alta concentração de sólidos; este tratamento é caracterizado pela fermentação da massa putrescível com concentração de sólidos totais em torno de $22 \%$; trata-se de uma alternativa relativamente nova, e é aplicada com o objetivo de recuperação de energia de biomassa apresentando, como principais vantagens, baixo requerimento de umidade e alta taxa de produção de gás (Tchobanoglous et al. , 1993).

Os processos de biodegradação anaeróbia têm sido empregados para diversos fins; historicamente, foram utilizados para bioestabilizar lodo de esgotos sanitários, utilizando-se o $\mathrm{CH}_{4}$ produzido (Metcalf \& Eddy, 1991).

Os processos anaeróbios tratam um número maior de substratos, devido ao fato das bactérias anaeróbias apresentarem características especiais, dentre as quais se pode citar a pequena taxa de utilização de energia para conversão em massa celular, sendo que grande parte se destina à formação de biogás.

O processo de bioestabilização anaeróbia da fração orgânica dos resíduos sólidos urbanos produzindo $\mathrm{CH}_{4}$ segue as mesmas etapas descritas para a bioestabilização de lodo (Barlaz, 1989).

Em princípio, todos os resíduos, quer sejam de origem animal ou vegetal, são bioestabilizados anaerobiamente e, no caso dos resíduos de origem vegetal, somente os componentes contendo lignocelulose são bioestabilizados e com muita dificuldade (Baader, 1991).

Vários modelos têm sido propostos para bioestabilizar anaerobiamente a fração orgânica putrescível dos resíduos sólidos, dentre os quais se destacam o modelo conceitual para bioestabilização anaeróbia de lodo biológico (Pavlhostathis, 1988) e o modelo para bioestabilização da fração orgânica putrescível dos resíduos sólidos urbanos e industriais (Leite, 1997).

Este trabalho objetiva analisar o comportamento dos sólidos totais e dos sólidos totais voláteis presentes nos resíduos sólidos urbanos e industriais submetidos ao processo de tratamento anaeróbio em reatores de batelada.

\section{MATERIAL E MÉTODOS}

Este trabalho foi realizado no Departamento de Hidráulica e Saneamento da Escola de Engenharia de São Carlos, USP, no período de abril de 1994 a dezembro de 1995 e os resíduos sólidos urbanos foram provenientes da Usina de Compostagem da CETESB, localizada na cidade de Novo Horizonte, SP, enquanto o lodo industrial utilizado como inóculo foi coletado na estação de tratamento de efluentes líquidos da indústria John Faber, situada no distrito industrial da cidade de São Carlos, SP.

Para a realização da parte experimental do trabalho, foram construídos, instalados e monitorados, quatro reatores. Na Figura 1 mostra-se o esquema de um dos reatores utilizados no trabalho experimental.

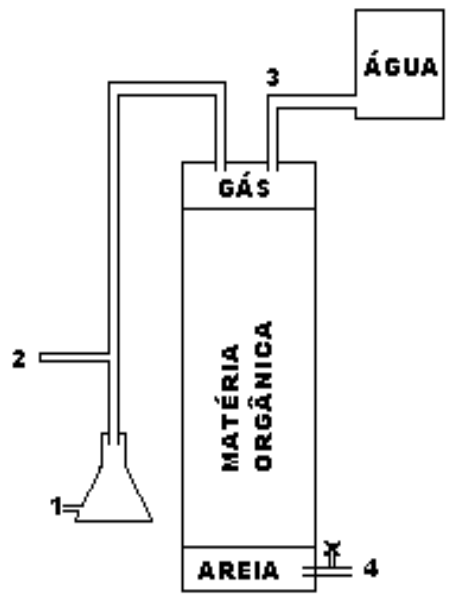

Figura 1. Reator utilizado no trabalho experimental

Nos reatores foram instalados os seguintes dispositivos :

Ponto 1 - registrador quantitativo do biogás produzido

Ponto 2 - coleta de biogás para análise cromatográfica

Ponto 3 - distribuidor de água adicionada ao interior do reator

Ponto 4 - torneira para coleta do percolado.

Na Tabela 1 são apresentados os principais parâmetros operacionais adotados no sistema experimental.

Tabela 1. Parâmetros operacionais dos reatores

\begin{tabular}{ccccccc}
\hline Reatores & \multicolumn{5}{c}{ Parâmetros } \\
\cline { 2 - 7 } & $\mathrm{TU}$ & $\mathrm{M}_{\mathrm{RSU}}$ & $\mathrm{M}_{\text {lodo }}$ & $\mathrm{M}_{\text {total }}$ & $\gamma$ & $\begin{array}{c}\mathrm{TOP} \\
(\%)\end{array}$ \\
& $(\mathrm{kg})$ & $(\mathrm{kg})$ & $(\mathrm{kg})$ & $\left(\mathrm{kg} \mathrm{m}^{-3}\right)$ & $(\mathrm{dias})$ \\
\hline $\mathrm{A}$ & 70,3 & 32,0 & 0,0 & 32,0 & 914,3 & 645,0 \\
B & 70,6 & 28,5 & 2,8 & 31,3 & 894,3 & 645,0 \\
C & 70,6 & 25,6 & 5,7 & 31,3 & 894,3 & 570,0 \\
$\mathrm{D}$ & 70,7 & 17,3 & 13,2 & 30,5 & 871,4 & 570,0 \\
\hline${ }^{*}$ TU - Teor de umidade, $\mathrm{M}_{\mathrm{RSU}}$ - Massa de resíduos sólidos urbanos, $\mathrm{M}_{\text {lodo }}$ - Massa de lodo, $\mathrm{M}_{\text {total }}-$ Massa
\end{tabular}

total, g - Peso específico, TOP - Tempo de operação dos reatores

Neste trabalho, a parte analítica foi realizada utilizando-se os métodos preconizados pelo Standard Methods for Examination of Water and Wastewater (APHA-AWWA-WPCF, 1992).

\section{RESULTADOS E DISCUSSÃO}

Na Tabela 2 são apresentados os resultados percentuais dos sólidos totais e dos sólidos totais voláteis presentes na massa "in natura”, utilizada como substrato na alimentação dos reatores. 
Tabela 2. Percentual de sólidos totais e de sólidos totais voláteis na massa "in natura"

\begin{tabular}{ccc}
\hline Reatores & \multicolumn{3}{c}{ Sólidos (\%) } \\
\cline { 2 - 3 } & Totais & Voláteis \\
\hline A & 29,7 & 47,6 \\
B & 29,4 & 45,4 \\
C & 29,4 & \\
D & 29,3 & 43,8 \\
\hline
\end{tabular}

Os dados da massa "in natura" de sólidos totais e de sólidos totais voláteis, alimentada aos reatores são apresentados na Tabela 3.

Tabela 3. Dados quantitativos da massa "in natura" de sólidos totais e de sólidos totais voláteis

\begin{tabular}{ccc}
\hline Reatores & \multicolumn{2}{c}{ Massa de Sólidos $(\mathrm{kg})$} \\
\cline { 2 - 3 } & Totais & Voláteis \\
\hline A & 9,6 & 4,5 \\
B & 9,4 & 4,2 \\
C & 9,4 & 4,1 \\
D & 9,2 & 4,0 \\
\hline
\end{tabular}

O substrato refere-se à massa constituída por resíduos sólidos urbanos mais, $5 ; 10$ e 15\% (em peso) de resíduos industriais alimentados, respectivamente, pelos reatores $\mathrm{B}, \mathrm{C}$ e D. O reator A foi alimentado somente com massa de resíduos sólidos urbanos, conforme se pode observar na Tabela 1.

Analisando os dados da Tabela 2, observa-se que o percentual de sólidos totais da massa "in natura" não apresentou variação significativa, enquanto o percentual de sólidos totais voláteis variou de 43,8 a 47,7\%. Esta variação se deve, basicamente, à heterogeneidade que apresentava na época a massa de resíduos sólidos urbanos utilizada neste trabalho de pesquisa.

No processo de bioestabilização da fração orgânica putrescível de resíduos sólidos é produzido percolado com elevada concentração de sólidos, principalmente nas primeiras fases do processo, isto é, na fase de hidrólise e acidogênese.

$\mathrm{Na}$ Figura 2 mostra-se o comportamento da evolução temporal da concentração de sólidos totais presentes no percolado produzido pelo processo anaeróbio de bioestabilização da matéria orgânica.

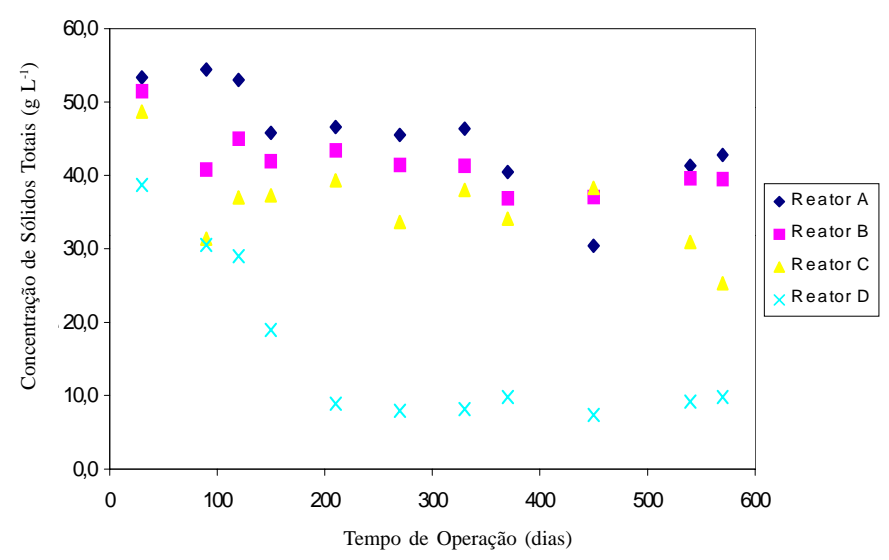

Figura 2. Comportamento da evolução temporal da concentração dos sólidos
Analisando-se o comportamento da Figura 2, observa-se que a concentração de sólidos totais sofreu mais rápida redução no percolado do reator D, isto é, com 210 dias de operação a concentração de sólidos totais já atingia o patamar de $8,9 \mathrm{~g} \mathrm{~L}^{-1}$, alcançando uma eficiência de redução na concentração de $77 \%$. Tomando-se como referência o tempo de 210 dias para os demais reatores, pode-se constatar eficiências de redução de 15,7, $16 \mathrm{e}$ $20 \%$, respectivamente, para os reatores A, B e C; isto justifica a influência do inóculo (lodo de esgoto industrial) utilizado no processo de bioestabilização anaeróbia da matéria orgânica, conforme mostrado na Figura 3.

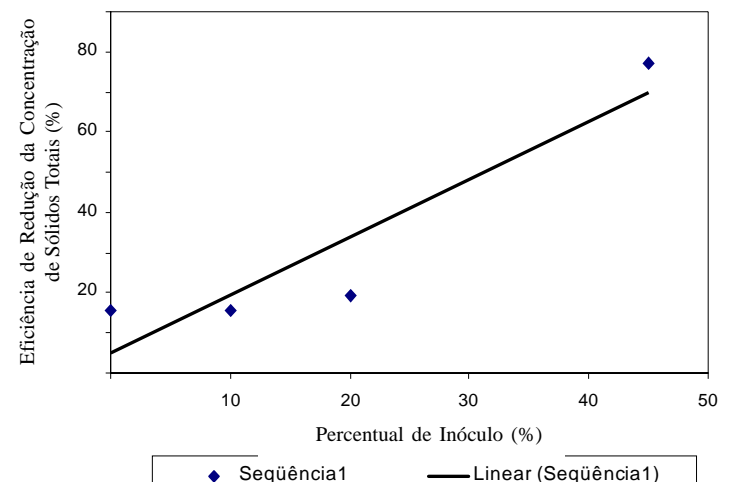

Figura 3. Correlação entre eficiência de redução da concentração de sólidos totais e o percentual de inóculo

Na Figura 4 apresenta-se o comportamento da evolução temporal da concentração de sólidos totais voláteis no percolado, durante o período de monitoramento dos reatores.

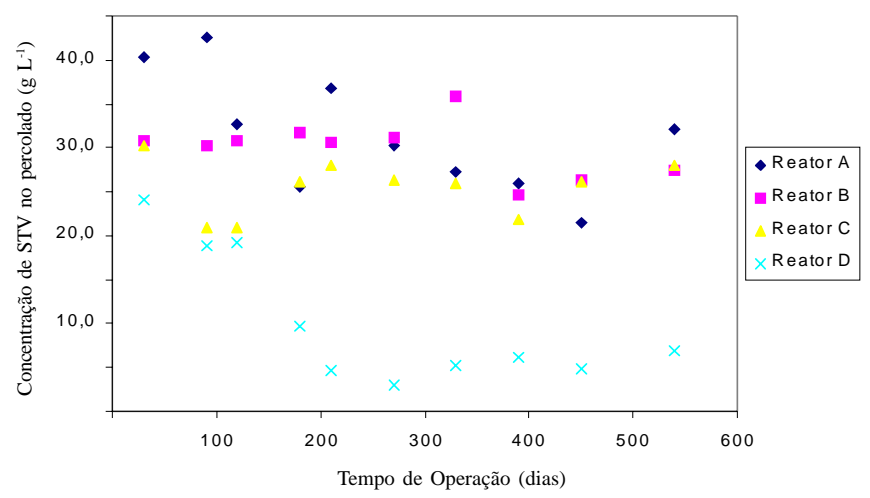

Figura 4. Comportamento da evolução temporal da concentração de sólidos totais voláteis

Levando-se em consideração o tempo de operação de 210 dias, observa-se que a redução da concentração de sólidos totais voláteis no percolado foi de $81 \%$ para o reator $\mathrm{D}$, enquanto para os demais reatores as eficiências alcançadas foram de 8,6, 0,6 e $7 \%$, respectivamente, para os reatores $\mathrm{A}, \mathrm{B} \mathrm{e} \mathrm{C}$, sendo estes valores inferiores aos apresentados pelos sólidos totais. A baixa redução da concentração de sólidos voláteis para o tempo de operação considerado se deve, ainda, à instabilidade do processo, causada sobretudo pela forte hidrólise do material particulado presente na massa de resíduos sólidos urbanos e industriais. Na Figura 5 pode-se observar o comportamento da influência do inóculo no processo anaeróbio de bioestabilização da matéria orgânica putrescível, quando considerados os sólidos totais voláteis. 


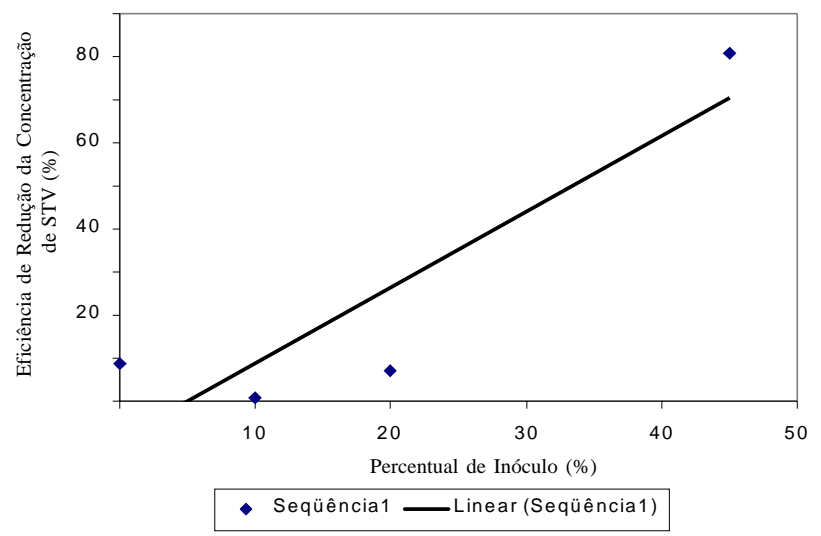

Figura 5. Relação entre eficiência de redução da concentração de STV e percentual de inóculo

A eficiência de transformação de massa de sólidos totais voláteis se deve a materiais de fácil biodegradação, tais como proteínas, açúcares, lipídios, amido etc.

Neste trabalho, a eficiência de transformação de massa de sólidos totais voláteis foi de $80,85,5,85$ e $93 \%$, respectivamente, para os reatores A, B, C e D e, para o tempo de operação, em torno de 570 dias.

Aplicando-se o conceito de demanda química de oxigênio na avaliação do processo anaeróbio de bioestabilização da fração orgânica putrescível dos resíduos sólidos urbanos em reatores de batelada, é possível dizer que a variação da massa de sólidos totais voláteis em função do tempo de detenção expressa, de forma indireta, o rendimento das atividades microbianas envolvidas no processo. Portanto, reportando-se às anotações do cálculo diferencial, pode-se representar o comportamento da massa de STV por uma função exponencial do tempo, resultando em um modelo do tipo:

$$
\frac{d M b}{d t}=-k M b
$$

Integrando-se a Eq. 1, resulta:

$$
M b=M b_{0} \cdot\left(1-e^{-k t}\right)
$$

em que:

$M b$ - massa de STV presente, em um tempo $t$

$M b_{0}$ - massa de STV inicial

$t$ - tempo de operação, (dias)

$k$ - constante de bioestabilização de primeira ordem $\left(\mathrm{dia}^{-1}\right)$.

Segundo Leite (1997), a Eq. 2 estima a massa de sólidos totais voláteis transformada, quando o sistema experimental é constituído por reatores com volume unitário de até $50 \mathrm{~L}$ e se tem dados suficientes para a determinação da constante de bioestabilização de primeira ordem.

Neste trabalho, a constante média de bioestabilização de primeira ordem determinada para os sólidos totais voláteis foi de $8,710^{-4}$ dia $^{-1}$, enquanto a taxa de produção média de gás metano foi de $154 \mathrm{NLCH}_{4} \mathrm{~kg}^{-1} \mathrm{STV}$ alimentado ao sistema. Vale ressaltar que os resíduos sólidos utilizados neste trabalho apresentavam, em média, $45 \%$ de sólidos totais voláteis, o que é pouco representativo para o bom desempenho do processo de bioestabilização anaeróbio. Para resíduos sólidos com percentuais maiores de sólidos totais voláteis, haverá maior acréscimo na taxa de produção de gás $\mathrm{CH}_{4}$, tornando esta alternativa de tratamento mais viável economicamente.

\section{CONCLUSÕES}

1. O processo de tratamento anaeróbio com alta concentração de sólidos, aplicado à fração orgânica putrescível dos resíduos sólidos urbanos inoculada com lodo de esgoto industrial, pode tornar-se uma alternativa promissora de destinação para esses tipos de resíduo sólido, considerando-se os aspectos técnicos, econômicos, sociais e ambientais.

2. A eficiência de transformação de massa de sólidos totais voláteis tende a ser mais representativa em função do percentual de inóculo utilizado na preparação do substrato.

3. O estado de equilíbrio dinâmico foi alcançado em período mais curto de tempo no reator $\mathrm{D}$, quando comparado com os demais reatores constituintes do sistema experimental.

4. A viabilidade técnico-econômica desse tipo de tratamento está condicionada a um percentual maior de sólidos totais voláteis, no substrato a ser tratado.

5. O comportamento dos sólidos totais não expressa, em sua plenitude, os mecanismos envolvidos no processo de bioestabilização anaeróbia da fração orgânica putrescível dos resíduos sólidos urbanos, haja vista na sua constituição química estarem presentes materiais de natureza extremamente complexas.

\section{REFERÊNCIAS BIBLIOGRÁFICAS}

ABNT (São Paulo, SP). NBR-10004, Resíduos sólidos classificação, 1987.

APHA, AWWA, WPCF. Standard methods for examination of water and wastewater. 18. ed. Washington: APHA, 1992.

BAADER, $W$. Biotechnological methods for the utilization of residues and byproducts of agricultural production. Institute for Technology, v. 32, 1991.

BARLAZ, M. Bacterial population development and chemical characteristcs of refuse decomposition in simulated sanitary landfill. Applied Environmental Microbiology, v. 55 n.1, p. 55-65, 1989.

LEITE, V.D. Processo de tratamento anaeróbio de resíduos sólidos urbanos inoculados com lodo de esgoto industrial. São Carlos: EESC/USP, 1997. 250p. Tese Doutorado

METCALF \& EDDY. Waste engineering: Treatment, disposal, refuse. 3 ed. New York: McGraw-Hill, 1991. 1334p.

PAVLOSTATHIS, S.G. Preliminary conversion mechanisms in anaerobic digestion of biological sludges. Journal of the Environmental Engineering, v. 114, n. 3, p.575 - 591, 1988. PEREIRA NETO, J.T. Resíduos sólidos domiciliares: um paradoxo da sociedade moderna. CONGRESSO BRASILEIRO DEENGENHARIA SANITÁRIAE AMBIENTAL, 17., Natal, Anais... Natal, 1993.

TCHOBANOGLOUS, G.T.; THEISEN, H.; VIGIL, S.A.Integrated solid waste managemente. Engineering principles and management issues. New York: McGraw-Hill, 1993. 978p. 